\title{
A Buddhist Propagation Competency Development Model of Administrative Monks in Sangha Administration Region 17
}

\author{
Phramaha Nakarin Sukrat (Analayo) ${ }^{1}$, Phramaha Yannawat Thitavaddhano², Intha Siriwan ${ }^{3}$, \\ Somsak Boonpoo ${ }^{4}$ \\ 1,2,3,4 Faculty of Education, Mahachulalongkornrajavidyalaya University \\ ${ }^{1}$ research.mcu@gmail.com, ${ }^{2}$ yannawat.bud@mcu.ac.th, ${ }^{3}$ intha.siri@mcu.ac.th, ${ }^{4}$ boonpoo999@ $@$ hotmail.com
}

\begin{abstract}
The purposes of this article were 1) to study the state of Buddhist propagation competency, 2) to develop a model of Buddhist propagation competency development, and 3) to propose Buddhist propagation competency development model of administrative monks in Sangha Administration Region 17. Mixed methods research was designed with 3 phases. Phase I was to study the state of Buddhist propagation competency using questionnaires to survey 234 monks. Data were analyzed by using percentage, mean and standard deviation. Phase II was to develop the model using interview with 15 key informants and content analysis was used for the analysis. Phase III was to propose the model and 9 experts were attended at focus group discussion, and data was analyzed by content analysis. Results showed that 1) the state of Buddhist propagation competency consisted of 3 aspects which were knowledge, skills, and personal characteristics. Overall level of practice was at high level. 2) There were 5 components in a model of Buddhist propagation competency development of administrative monks in Sangha Administration Region 17 which were (1) principles, (2) objectives, (3) procedure, (4) process development applying the threefold training as Buddhist principle encouraging the propagation competency development compose of content, objective, learning management, teaching media, activities, method of development and assessment, and (5) learning assessment. 3) Buddhist propagation competency development model of administrative monks in Sangha Administration Region 17 was appropriate in competency development for contribution of happiness to communities and Thai society.
\end{abstract}

Keywords

Model, Buddhist Propagation, Competency, Administrative Monks

Article Received: 10 August 2020, Revised: 25 October 2020, Accepted: 18 November 2020

\section{Introduction}

Buddhism therefore flourished in Thailand has been a model for Thai people's lives for a long time. Moreover, Buddhism is the religion that brings people and society to the development of mind and wisdom through various methods of practice [1], and to promote mental training and intelligence training to achieve true enlightenment [2], with Dharma practice centers scattered throughout the country. Almost every community has strengthened the Thai people both mentally and wisdom. It is able to cope with all kinds of problems enabling Thai people to live happily in the midst of various environments as well. Therefore, the traditional Thai community has a way of life dependent on nature, self-sufficiency, generous living in the community, support and share with each other, living in kindness, generosity, having a family as a means of binding people in the community together [3].

The practice and life of monks according to the Dharma Vinai will build faith. It is an incentive for Buddhists to be happily coexist in society indicates the success of promoting Buddhism to be sustainable and permanent. As the word said Buddhism is the national religion and can continue to flourish forever, with the reliance on the Sangha, therefore the highest-ranking monk and is of great importance as the leader of the temple administration and maintenance in order to be in good order that has important duties related to governance, religious education, education, work, propagation, public utilities, and public welfare until it says "Buddhism will prosper because of the devotion of the people. Monks are indeed the main person to develop temple to propose the prosperity of Buddhism, so the development of the temple is the center of the community. Monks must be persons respected by the people, and it is the faith of the people" [4].

In the Sangha Administrative Region of Region 17, the Sangha of the Region 17 consists of 5 provinces, namely Krabi, Phang Nga, Phuket, Ranong and Trang, where the Sangha has performed duties as both a Sangha (Sangha Leader) who spread Buddhism to Buddhists, and is the authority and duty under the Sangha Act and the Sangha Association of many important laws especially to control and promote the maintenance of good tidiness, religious education, education and work Buddhism Public assistance and public welfare to go smoothly[5].

From the previous research, many issues have found the problem of Buddhist propagation of the monks, which is the problem of Buddhism. The propagation of Buddhism in the 21 st century, if the monks who are the center of Buddhism ignore, does not develop propagationcompetencies probably because of the work of an abbot level. Dharma teacher may be redundant, lack of clarity, using people who are not suitable for the job, lack of a system of motivation, and lack of performance appraisal criteria [6]. In addition, the research also found a solution to the problem of Buddhist propagation, that is, the abbot level monks should have the capacity to propagate and manage the monastic affairs in order to be orderly success in promoting Buddhism because of the propagation of the Abbot level. The essence is to expand the teachings of the Dharma. It is the practice of Dharma, which is the practice of indifference which arises from the continuous 
development of the missionary competence, thus creating the great of Buddhism to be seen and proven [7].

It showed that the Sangha is very important to the administration of the Sangha which if the monks do not have knowledge and ability to spread Buddhism, it may cause the administration of the Sangha and the propagation of Buddhism to not be as successful as it should be. Hence, it is necessary to develop the capability of spreading Buddhism to the monks by integrating the principles and concepts of competence to the propagation of Buddhism in order to develop the monks to be more effective in propagating from the background and significance of the problems mentioned above. The researcher is interested to study a model for the development of Buddhism competency of the monks in the Sangha Administration Region 17, in order to develop the monks to be capable of spreading Buddhism and to benefit the administration of the Sangha in the propagation of Buddhism in the Sangha Administration Region 17 continually.

\section{Research Objectives}

The purposes of this article were 1) to study the state of Buddhist propagation competency, 2) to develop a model of Buddhist propagation competency development, and 3) to propose Buddhist propagation competency development model of administrative monks in Sangha Administration Region 17.

\section{Research Methods}

Mixed methods research was designed for this research and 3 steps were conducted as follows:

Step 1: to study the state of Buddhist propagation competencyof the monks in Sangha Administration Region 17 by studying documents on the characteristics of the evangelical competencies. Questionnaire was used to collect data from the monks in the 17 ecclesiastical area, which consisted of 576 for the population, and the sample were 234 samples of the monks by opening a sample size table of Krejcie, R. V. \& Morgan, D. W. [8].The data were analyzed by descriptive statistics such as percentage, mean and standard deviation.

Step 2: Develop a model for the development of Buddhism competency of the monks in Sangha Administration Region 17 by studying the documents related to the principles and methods for the development of personal competency. Buddhist principles are used to support and to create interview questions about competency development techniques and the application of Buddhist principles to support competency development by 15 key informants in the interview and analyzed the data by using content analysis.

Step 3: propose Buddhist propagation competency development model of administrative monks in Sangha Administration Region 17, qualitative research was designed by organizing focus group discussion with experts to determine the suitability of the model by the experts who participated in the group discussion, 9 experts were selected according to purposive sampling with knowledge of competency development and have knowledge about the propagation of Buddhism, and data was analyzed by using content analysis.

\section{Results}

1. The performance of Buddhism propagation of the monks in the Sangha Administrative Region 17, in general, had a high level of practice and when classified by each side found at high level in all 3 areas: knowledge, skills and attributes.

2. There were 5 components in a model of Buddhist propagation competency development of administrative monks in Sangha Administration Region 17 which were (1) principles, (2) objectives, (3) procedure, (4) process development applying the threefold training as Buddhist principle encouraging the propagation competency development compose of content, objective, learning management, teaching media, activities, method of development and assessment, and (5) learning assessment, which called the CIPP Model as in Fig. 1.

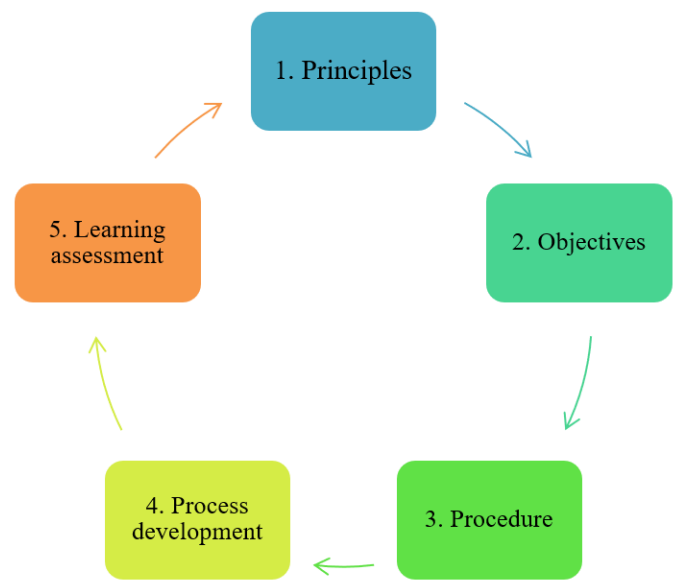

Fig. 1 A Buddhist Propagation CompetencyDevelopment Model of Administrative Monks in Sangha Administration Region 17

3. Buddhist propagation competency development model of administrative monks in Sangha Administration Region 17 was appropriate in competency development for contribution of happiness to communities and Thai society as well.

\section{Discussions}

The researcher found important points to be discussed as follows:

1. The status of the Buddhist propagation competencies of the monks in the Sangha Administrative Region 17 in all 3 areas, namely Knowledge, Skills and Attributes, in general, the level of performance was at a high level. When considering the aspects from the areas with the highest to least performance rank, it was found that the attributes were at the level 1 of the performance level, Knowledge competencies were ranked at 2, and the competency in skills has a level of practice in the third rank, probably because the present monks have a higher level of religious and secular education especially at the university level. In addition, it is consistent with the research of 
Phramaha Saranakhai Mahapunho showed that the development of the monks have progressed in their propagation, and the language skills of the present day. They are ready to speak, sermons, lectures, write and print Buddhist texts and compose textbooks in literature, academic texts, including focusing on people having leaders. It is considered to follow teaching in theory and practice at the same time. Therefore, it should have a short-term plan and long-term plans to train monastic leaders both in theory and in practice by organizing a policy hearing principles of propagation and practice of speaking sermons, lectures and producing media in various forms of propagation of Buddhism in order to be able to proactively and effectively carry out missions [9]. It is consistent with the research of Chot Bodirat, the state where the research results showed promoting the monks to study and develop leadership. There is a development of competency and administrative workload by training the Sangha to be the leader in mental development, ethics, morality, and to have the knowledge and skills to prevent Buddhists from losing their faith in Buddhism and to continue to believein Buddhism [10].

2. A model for developing the capability of Buddhism propagation of the monks in the Sangha Administrative Region 17, was a model development through document synthesis and interviews with 15 experts, then drafted a model for the development of Buddhism competencies of the monks in the Sangha Administrative Region 17, consisting of 5 elements: (1) principles, (2) objectives, (3) procedure, (4) process development applying the threefold training as Buddhist principle encouraging the propagation competency development compose of content, objective, learning management, teaching media, activities, method of development and assessment, and (5) learning assessment. A competency development model that is suitable for the development of the Buddhist missionary competence of the monks related to Phrarajchamethi's research work and the research results showed the guidelines for the development of the monks' competency development consisted of knowledge (Knowledge) 1) Sangha law, rules, regulations, resolutions and announcements of the Supreme Sangha Society for disclosure, 2) Policy, strategic plans and leading to propagation practice, 3) Education Buddhism by learning both theory and practice, 4) techniques and methods of propagating Buddhism, 5) techniques and methods of preaching, and 6) application of information technology media on propagation [11] and also related to the research of Phramahatharuti Wirojno (Rungchai Witoon)where the research results were development of the Sangha in the administration of the current Thai Sangha in the propagation of Buddhism is a development for the monks to have progress in propagating and the language skills of the present day focused on people to practice Dharma according to the power of faith considered. It was an order exam in the theory and perform at the same time [12].

3. The results of the presentation of a model for the development of Buddhism competency of the monks in the Sangha Administrative Area, Region 17, consists of 5 elements:(1) principles, (2) objectives, (3) procedure, (4) process development and (5) Evaluation, which experts commented that it is appropriate and feasible for the development of the Buddha's missionary competencies in the Sangha Area. The propagation of Buddhism of the
Sangha in the Sangha Administrative Region 17, which is the result of this research is a complete model development process according to the 3-step model development approach, as follows:The first step was the study of the Buddhist propagation competency of the monks in the Sangha AdministrativeRegion 17 by studying the documents analyze data through content analysis. The sampling questionnaire was used by 234 samples and analyzed the data by descriptive statistics such as frequency, percentage, mean and standard deviation, and presented in the form of a table with a description. Step 2 Development of the model by studying documents, analyzing data with content analysis and interviewing 15 key informantswith tools for research, namely interview form and data analysis by content analysis. Step 3, the proposal of the model by discussing a group of 9 experts, the research tools were questions for focus group discussion, and perform data analysis with content analysis. This is related to Thawatchai Rattanyoo said that model development is a process of creating or developing a model containing the study of related knowledge of model sketching and to investigate the suitability and feasibility of the try out model [13].

\section{Recommendations}

\section{A. Recommendations for practices}

Government Sector, National Buddhism Office and related agencies should do the following:

1) This research should be applied to achieve a concrete development of the Buddhism competency of the Sangha in the Sangha Region17 which is useful and necessary for the administration of the clergy.

2) This research should be used to develop a manual for the development of the Buddhism competency development of the monks in the Sangha Administrative Region 17.

3) This research should be organized a meeting of the PatriarchsRegion 17, to have an agreement to cooperate in building a network of Buddhism propagation of the monks at all levels.

\section{B. Recommendations for further research}

1. Should focus on the development of the knowledge of Buddhism propagation (Knowledge) is 1) Sangha Law, Sangha Act, including the law of the country that is beneficial to the propagation of Buddhism. 2) Restoration, restoration a building inside a temple to develop and improve the measure to be suitable for the propagation of Buddhism, and 3) Meditation and Vipassana meditation.

2. Emphasis should be placed on the development of Buddhism competency in skills that are 1) fundraising skills to fund the propagation of Buddhism, 2) skills of managing local culture education resources, and 3) skills in organizing in the proactive propagation of Buddhism.

3. Emphasis should be placed on the development of the propagation competency of personal attributes: 1) Faith and spiritual leadership for society, 2) Propagation qualifications, and 3) Personal behavior being as a good role model with a public mind, and help support including share 
your physical and mental happiness for those who are in distress.

\section{Conclusion}

The research paper on the development model of Buddhist propagation competency of the monks in the Sangha Area Region 17, is a combination of both quantitative and qualitative research. It is a development model for the development of Buddhism competency of the monks in the Sangha Administrative Region 17, consisting of 5 components: (1) Principle, (2) Objectives, (3) Action system, (4) Development process. It consists of Buddhist principles that promote the development of the Buddhism competency, namely the Trisikkha principle and the competency development process is the essence, objectives, learning management, media, equipment, activities, development methods, evaluation methods. (5) Evaluation and summary of knowledge based on this research;it was called CDB MODEL that was the process of developing the monks'competency for the propagation.

$\mathrm{C}=$ Competency, Competency is the competency of Buddhism propagation of the monks in 3 areas, which are: 1. Knowledge of Buddhism consists of 1) Sangha Law, Sangha Act, as well as government law that is beneficial. 2) The restoration of buildings and places in the temple, to develop and improve the temple to be suitable for the propagation of Buddhism. 3) Meditation and Vipassana meditation 2. The skills of Buddhism propagation skills consisted of 1) Fundraising skills to fund the propagation of Buddhism, 2) Management skills of local cultural learning resources, 3) Proactive Buddhism skills 3. The characteristics of personal characteristics of Buddhism (Attributes) consisted of 1) leadership of faith and spirituality for society, 2) the qualifications of the Dhamma mission, and 3) behavior as a model of good character and public mind, help, support, and share your physical and mental happiness for those who are in distress.

$\mathrm{D}=$ Development, Development is the development of the monks to be knowledgeable and competent according to the Buddha's propagation capacity, including 1) workshops and academic seminars to achieve knowledge, skills, and personal attributes, 2) Group discussion to learn and exchange about knowledge, skills and personal attributes. 3) Learning knowing from action learning to achieve knowledge, skills and personal attributes.

$\mathrm{B}=$ Buddhism, Buddhism is a Buddhist principle that promotes the development of Buddhism competency, namely, the Trisikkha principle, namely 1) the precepts, the practice for the training of high conduct, 2) the meditation, the practice for training the mind for Moral, 3) wisdom, practices for training intelligence to achieve high enlightenment as shown in Fig. 2.
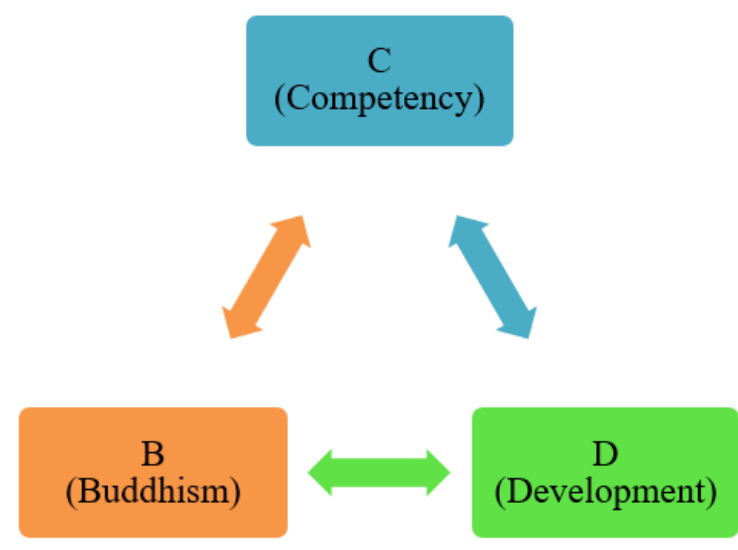

Fig.2CDB MODEL

\section{References}

[1] Phra Dhammapitaka (P.A.Payutto), Bhutthadham, 3rd edition, Bangkok: Thammapha, 1998.

[2] Phra Brahmagunabhorn (P.A. Payutto), Buddhist Dictionary, Code of Dhamma, 25rd ed. , Bangkok: Sahathamik, 2013,Expanded version of Dharma, Bangkok: Palitham, 2015.

[3] Phrarajchamethi (Vicha Apipanyo),"Development of the competency of the district monks in the Sangha Administrative Region. 8 ", Ph.D. Thesis, Graduate School: Mahachulalongkornrajavidyalaya University, 2016.

[4] Phra Dharmawarodom, Temple domination, Bangkok: Religion, 1996.

[5] Phrarajchamethi (Vicha Apipanyo), 'Development of District-level Monks' Competency Development in the Sangha Administrative Region 8", Ph.D. Thesis, GraduateSchool,

Mahachulalongkornrajavidyalaya University, 2016.

[6] T. Chinsongthiraphanit, "Development of Missionary Competency of the Abbotry Monks", Ph.D. Thesis in Buddhism, Graduate School, Mahachulalongkornrajavidyalaya University, 2016. 
[7] Krejcie, R. V. \& Morgan, D. W. Determining Sample Size for Research Activities. Educational and Psychological Measurement, 30(3), (1970) : 607 - 610.

[8] Phramaha Sornakhai Mahapunyo, "The development of the monks' administration in the Globalization ", Doctor of Buddhism Thesis, Department of Public Administration, Graduate School, Mahachulalongkornrajavidyalaya University, 2013.

[9] C. Bodirat, In the Sangha Administrative Area, Region 4 for the Security of Buddhism", Ph.D. Thesis of State Administration of Religious Studies, Graduate School, Valaya Alongkorn Rajabhat University, 2012.

[10] Phrarajchamethi (Vicha Apipanyo), 'Development of the Monks' Competency at District Level in the Sangha Administrative Region, Region 8", Ph.D. Thesis, Graduate School, Mahachulalongkornrajavidyalaya

University, 2016.

[11] Phramahatharuti Wirojno (Rungchai Witoon), "The Development Model of the Sangha for the Efficiency of Sangha Administration", Ph.D. Thesis of Buddhism, Graduate School, Mahachulalongkornrat University College, 2013.

[12] T. Rattanyoo, "School-based administration model development in schools under the local administrative organization", Ph.D. Thesis. Educational Administration Program, Graduate School, Siam University, 2008. 